\title{
BATCH ELECTROCOAGULATION PROCESS FOR REMOVAL OF CHROMIUM FROM TANNERY WASTEWATER
}

\author{
Md. Anik Hasan, Md. Abul Hashem*, Md. Navid Arman and Md. Abdul Momen \\ Department of Leather Engineering, Khulna University of Engineering \& Technology, Bangladesh
}

Received: 19 June 2019

Accepted: 12 November 2020

\begin{abstract}
This study was aimed to investigate the chromium removal from the tannery wastewater through electrocoagulation. The zinc and copper plates were used as electrodes for the electrocoagulation process. The effectiveness of the electrocoagulation for chromium removal efficiency was examined investigating various parameters: applied voltage, time, and current density. In batch experiment, $500 \mathrm{~mL}$ chromium-containing wastewater was used for electrocoagulation. Chromium content in the raw wastewater and after treatment at optimized conditions was 340.1 and $6.9 \mathrm{mg} / \mathrm{L}$, respectively. The efficiency of chromium removal and reduction of biochemical oxygen demand (BOD) was at 98.0 and 64.6\%, accordingly. Although total dissolved solids (TDS) was slightly increased. The increment of current density enhances forming zinc hydroxide which causes the damage of electrodes. Electrocoagulation is an effective technique to remove chromium from the wastewater especially from the tannery wastewater.
\end{abstract}

Keywords: Chromium; Current density; Electrocoagulation; Electrodes; Tannery effluent.

\section{INTRODUCTION}

Although the contribution of the tanning industry tothe world economy is meritorious, it consistently envisaged criticisms due to a remarkable contribution to environmental pollution (Pal et al., 2020). The global leather market is about US $\$ 80$ billion in 2018 and expected it will extend to US \$128 billion by 2022 (Sivaram and Banik, 2019). Eventually, tanneries discharge $30-35 \mathrm{~m}^{3}$ wastewaters during processing $150 \mathrm{~kg}$ of hide/skin. These large volumes of wastewater contain a high amount ofchromium, sodium, chloride, total dissolved solids (TDS), sulfide, nitrogen, biochemical oxygen demand (BOD), chemical oxygen demand (COD), dyes which are far above from the acceptable range (Chowdhury et al., 2015). Kothai et al. (2019) have investigated that tannery wastewater contains different types of heavy metals like chromium $(\mathrm{Cr})$, zinc $(\mathrm{Zn})$, led $(\mathrm{Pb})$, nickel (Ni) which are nonbiodegradable and carcinogenic. Wastewater containing toxic heavy metals and dyes creates an adverse effect on the ecosystem as well as human health (Kamaraj et al., 2020).

Tannery effluent contains the highest amount of pollutants comparing with all other industrial wastes. Especially, tanneries are a large contributor to chromium pollution (Belay, 2010). Statistic show around 90\% tanneries are usingbasic chromium sulfate as a basic chemical in tanning operation and only tanning wastewater contain around $4000 \mathrm{mg} / \mathrm{L}$ chromium which is much higher than the maximum permissible limit set by WHO (Saravanabhavan et al., 2004). The tannery wastewater decreases the quality of water bodies into which they are discharged. The result of the disposition of chromium-containing tanning effluent into the environment is much serious as the $\mathrm{Cr}$ ion leached out from the effluent and pollute soil and water body then finally enters into the human body via food chain (Sarker et al., 2013). How the physiochemical properties of groundwater, surface water, and soil are changes with the contamination of chromium is demonstrated and the final effect of chromium contamination on aquatic and terrestrial life is also observed e.g., trivalent chromium is harmful to aquatic life and fish at excess level ( $>5.0$ $\mathrm{mg} / \mathrm{L}$ ) (Overah, 2011). Chromium exists in the natural environment in two forms: trivalent, $\mathrm{Cr}(\mathrm{III})$, and hexavalent, $\mathrm{Cr}(\mathrm{VI})$, tannery wastewater contains both the form. Based on toxicity $\mathrm{Cr}(\mathrm{VI})$ is more toxic and shows more mobility compare to Cr(III) (El-Taweel et al., 2015). Like other heavy metals, chromium shows a nonbiodegradable character that can accumulate itself in the human body and causing serious health damage like hemorrhaging, lung malignancy, itching, chest pain, ulceration, profuse sweating, and skin irritation (Yahya et al., 2020; Mohan et al., 2006). Problems caused by chromium could be minimized if the chromium-containing tannery wastewater is treated before discharge to the environment.

Numerous techniques have been employed to remove such toxic metal from the tannery wastewater like ion exchange, coagulation/flocculation, membrane filtration, adsorption, reverse osmosis, and precipitation (Kusku et al., 2014; Obayomi et al., 2020; Koushkbaghi et al., 2018). Among them, the coagulation/flocculation method has achieved much popularity because of its simplicity but the main disadvantages of this technique are it causes secondary pollution due to the use of the excess amount of chemicals (Lefebvre and Moletta, 2006; Kumer et al., 
2018). Recently many researchers have shown their interest in electrocoagulation technology for the treatment of wastewater, the reason behind that compared to other technology it has some attractive advantages like environmental friendliness, cost-effectiveness, simple in application, have the ability to reduce the possibility of secondary pollution (Ghernaout et al., 2011). In the recent past, the electrocoagulation technique has been applied for the treatment of different industrial wastewater, municipal wastewater (Makwana and Ahammed, 2016), Dairy wastewater (Aitbara et al., 2014), Pharmaceutical wastewater (Khaldi et al., 2017), and Distillery wastewater (Thakur et al., 2009). Mavrov et al. (2006) have also investigated that the electrocoagulation technique can remove $90 \%$ selenium from the copper industry.

The goal of the present study is to utilize the electrocoagulation process to remove tannery chromium from industrial wastewater. The performance of the electrocoagulation process was determined to investigate different parameters: applied voltage, current, and time using zinc $(\mathrm{Zn})$ and copper $(\mathrm{Cu})$ electrodes. Besides different water quality parameters: $\mathrm{pH}$, turbidity, conductivity, TDS, and BOD has also been investigated.

\section{EXPERIMENTAL PROCEDURE}

\subsection{Collection of Wastewater}

Wastewater sample from chrome tanning operation was directly accumulated from SAF Industries Ltd. Situated in Noapara, Jashore, Bangladesh. Sampling was conducted in a plastic vessel after washing with nitric acid and rinsing with a wastewater sample. The wastewater was stored in the laboratory immediately after collection.

\subsection{Chemicals}

The reagents utilized in this experiment were of analytical grade. The chemicals were obtained from a local scientific shop in Khulna, Bangladesh.

\subsection{Physico-chemical Parameter}

The untreated and treated spent chrome liquor as characterized through the following parameters: chromium content, $\mathrm{pH}$, turbidity, electrical conductivity (EC), total suspended solids (TSS), TDS, BOD, and COD, and compared with a standard value. All measurement was maintained in triplicate.

\subsubsection{Chromium Analysis}

SLC 208 titrimetric method of SLTC (Society of Leather Technologist and Chemists) (SLTC, 1996) was carried out to determine chromium concentration in initial and final treated liquor. The experiment was initiated with a $50 \mathrm{~mL}$ wastewater sample in a conical flask of $500 \mathrm{~mL}$ volume. After mixing $20 \mathrm{~mL}$ nitric acid and $20 \mathrm{~mL}$ of concentrated sulphuric acid andperchloric acid mixture, the flask was heated until the solution turned into red brick colour. Extra 1-minute continued heating and quickly cooled down in a water bath. Distilled water $(100 \mathrm{~mL})$ and few glass beads were mixed with the solutions and boiled for 10 minutes for chlorine removal. $10 \mathrm{~mL}$ of $30 \%$ concentrated sulphuric acid was added after cooling and took for titration with ferrous ammonium sulfate. Few drops (5-6) of indicator ( $N$-phynylanthralinic acid) were used and the green color denoted the endpoint of the titration.

\subsection{2 pH Measurement}

The $\mathrm{pH}$ meter (UPH-314, UNILAB, USA) at first was calibrated with a two-point standard solution at $\mathrm{pH} 4.01$ and $\mathrm{pH} 7.00$, respectively. Then it was used for $\mathrm{pH}$ determination during the experiment.

\subsubsection{Determination of TSS, TDS, EC, and turbidity}

APHA-2540D method was carried out for TDS and TSS analysis of chromium-containing wastewater and treated liquor. The wastewater sample was filtered through weighed filter paper (Whatman No. 1) and the filtrate was dried at $105 \pm 2{ }^{\circ} \mathrm{C}$ until a constant weight was gained. TSS was calculated from the suspended dry matter on the filtered paper and TDS from the dried filtrate. EC and the turbidity were measured by a conductivity meter (CT676, BOECO, Germany) and a portable turbidity meter (Hach 2100Q, 2100Q, Germany) respectively.

\subsubsection{Determination of BOD}

APHA method 5210 B (APHA, 2012) as carried out for BOD determination. The wastewater was diluted at the desired level and the BOD bottle was filled with the diluted sample $(300 \mathrm{~mL}) .1 \mathrm{~mL}$ of manganoussulfate, alkaline azide solution, and concentrated sulphuric acid were added with the sample avoiding any form of air bubbles, and shaken. Then the sample was titrated with sodium thiosulfate $(0.02 \mathrm{~N})$ to find out the initial dissolved oxygen 
(DO). Another BOD bottle containing a diluted sample was kept in an incubator at $20 \pm 1^{\circ} \mathrm{C}$. After 5 days the BOD was taken out from the incubator and the same process was followed as described earlier to measure the final DO. Finally, $\mathrm{BOD}_{5}$ was calculated from the initial DO and finally DO by using the following formula

$$
\mathrm{BOD}_{5}=\left(\mathrm{DO}_{\mathrm{i}}-\mathrm{DO}_{\mathrm{f}}\right) \times \mathrm{D} . \mathrm{F}
$$

Where $\mathrm{DO}_{\mathrm{i}}$ is the initial DO, $\mathrm{DO}_{\mathrm{f}}$ is the final $\mathrm{DO}$ and D.F is the dilution factor.

\subsection{Batch-wise electrocoagulation test}

Fig. 1 represents the schematic illustration of the electrocoagulation process. The experiment was conducted in a round shape glass beaker (height $14.5 \mathrm{~cm}$ diameter $11 \mathrm{~cm}$ ) with a volumetric capacity of $1000 \mathrm{~mL}$. A zinc plate $(13.20 \mathrm{~cm} \times 5.30 \mathrm{~cm})$ and copper plate $(13.20 \mathrm{~cm} \times 5.30 \mathrm{~cm})$ acted as anode and cathode respectively. During the batch experiment, $600 \mathrm{~mL}$ chromium-containing wastewater was used in the coagulation cell where two electrodes were set down vertically and parallel in the wastewater. Direct current (DC) was supplied to the electrodes and at different time intervals, $50 \mathrm{~mL}$ supernatant was taken from the top of the reactor for chromium measurement.

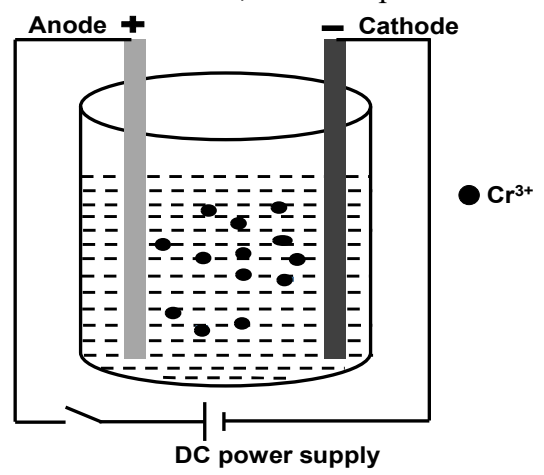

Figure 1: Electrocoagulation process

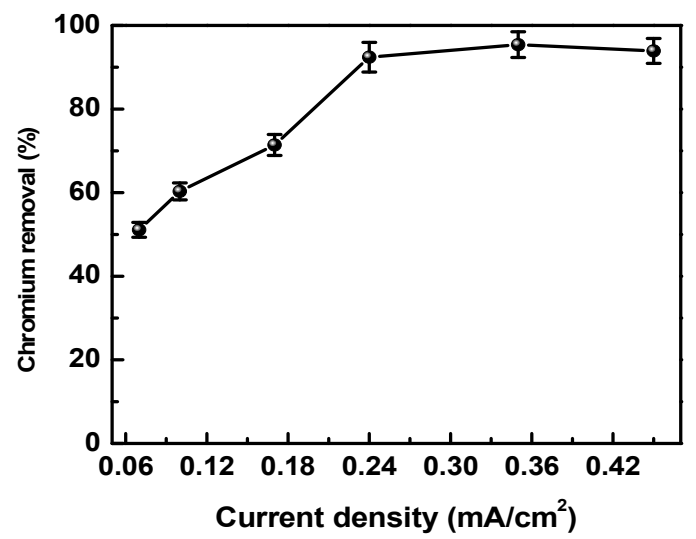

Figure 3: Effect of current density on chromium removal efficiency

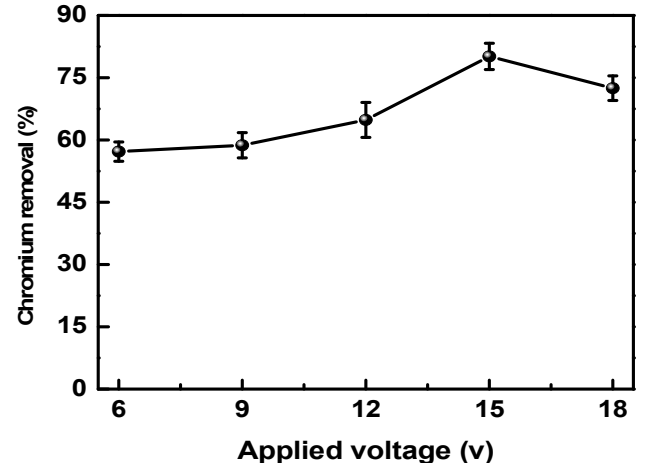

Figure 2: Effect of applied voltage on chromium removal efficiency

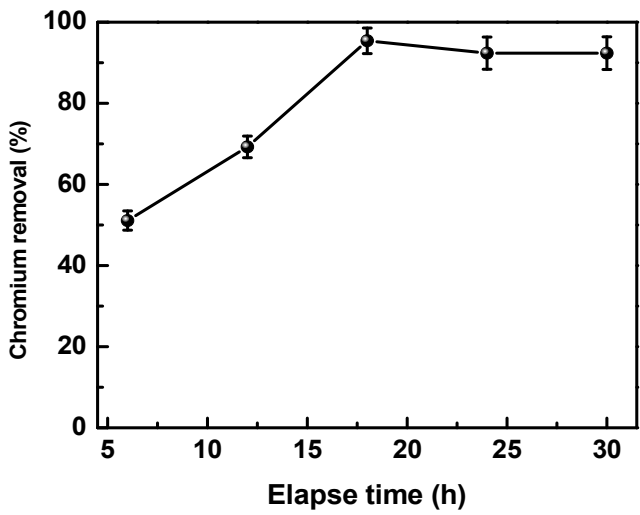

Figure 4: Effect of time on chromium removal efficiency

The Electrocoagulation process involves the generation of coagulants and form co-precipitation. Water is ionized by DC supply and produce hydroxyl radical and hydrogen gas. In the cell, the following reactions occur:

$$
2 \mathrm{H}_{2} \mathrm{O}+2 \mathrm{e}^{-} \Leftrightarrow \mathrm{H}_{2}+2 \mathrm{OH}^{-}
$$

Anode (oxidation) $: \mathrm{Zn} \Leftrightarrow \mathrm{Zn}^{2+}+2 \mathrm{e}^{-}$

$$
\mathrm{Cr} \Leftrightarrow \mathrm{Cr}^{3+}+3 \mathrm{e}^{-}
$$

Co-precipitation : $\mathrm{Cr}^{3+}+3 \mathrm{OH}^{-} \Leftrightarrow \mathrm{Cr}(\mathrm{OH})_{3}$

$$
\mathrm{Zn}^{2+}+2 \mathrm{OH}^{-} \Leftrightarrow \mathrm{Zn}(\mathrm{OH})_{3} \text { (at high curent density) }
$$

\subsection{Optimization of the Batch Experiment}

The electrocoagulation process was optimized in a batch-wise experiment to obtain the optimum conditions viz. applied voltage, time, and the current density. The chromium removal percentage was considered during optimization. 


\subsubsection{Voltage Optimization}

A predefined voltage was applied during the electrocoagulationprocess and the voltage was controlled by using a digital multimeter (CD 800, Japan). A $600 \mathrm{~mL}$ wastewater sample was poured into the electrocoagulation chamber and applied $6,9,12,15$, and $18 \mathrm{~V}$, respectively. After treatment, supernatant was restocked for chromium measurement. For each applied voltage, a triplet batch experiment was conducted.

\subsubsection{Time Equilibrium}

For time optimization, predefined time e.g., 6, 12, 18, 24, and 30h, $600 \mathrm{~mL}$ of sample was treated in the electrocoagulation chamber and then repeated with a new wastewater sample. To obtain the optimal time, chromium content was measured of the supernatant. The experiment was continued in a triad.

\subsubsection{Optimizing Current Density}

For optimum current density, defined current $0.07,0.10,0.17,0.24,0.36$ and $0.46 \mathrm{~mA} / \mathrm{cm}^{2}$ was passed through the electrocoagulation process after defined time interval and sample was withdrawn and refilled with untreated wastewater. The withdrawn samples were examined for $\mathrm{Cr}$ content and the procedure was continued in a triad. A digital multimeter (CD 800, Japan) was used to monitor the current density.

\section{RESULTS AND DISCUSSION}

\subsection{Optimal Voltage}

Applied voltage plays a significant role in the electrocoagulation process as total energy consumption depends on it. In batch experiment, the chromium removal efficiency was observed at different voltages: 6, 9, 12, 15 and 18 $\mathrm{V}$ by the electrocoagulation process. It is clear from Fig. 2 that applied voltage has a positive effect on the chromium removal efficiency as chromium removal efficiency was increased with the increase of applied voltage. For applied voltage 6,9 and $12 \mathrm{~V}$ chromium removal efficiency was obtained by $57.2,58.7$ and $64.8 \%$, respectively. It seems that by increasing the applied voltage up to $12 \mathrm{~V}$, the chromium removal efficiency was increased very slightly. In case of applied voltage $15 \mathrm{~V}$, the chromium removal efficiency was maximum (80.1\%). Bhatti et al., (2011) observed the same phenomena and they found maximum chromium efficiency at $12 \mathrm{~V}$. Unfortunately, above-applied voltage $>15 \mathrm{~V}$, the chromium removal efficiency was decreased (72.5\%). Therefore, the applied voltage was selected $15 \mathrm{~V}$ for chromium removal through the electrocoagulation process.

\subsection{Optimal Current Density}

Electrocoagulation process was significantly affected by the current density as it has a great effect on the pollutant removal rate and it is considered as one of the most important parameters (Aoudj et al., 2012). With applied current density viz. $0.07,0.10,0.17,0.24,0.36$ and $0.46 \mathrm{~mA} / \mathrm{cm}^{2}$; chromium removal efficiency was found 51.1 , $60.3,71.4,92.4,95.4$ and $93.9 \%$, respectively. It is quite clear that with the increase the current density chromium removal also increased. According to Faraday's law, this type of phenomena was observed due to anodic dissolution (El-Taweel et. al., 2015). It is obvious from Fig. 3 that there was a good linear relationship between current density $\left(0.07,0.10,0.17,0.24 \mathrm{~mA} / \mathrm{cm}^{2}\right.$; correlation coefficient $\left(R^{2}=0.983\right)$ and chromium removal efficiency. The chromium removal efficiency for the current densities $0.24,0.36$, and $0.46 \mathrm{~mA} / \mathrm{cm}^{2}$ was almost same $(92.4,95.4$ and 93.9\%).

At elevated current density, there is a strong possibility to form a high amount of hydrogen bubbles in the cathode that will cause the uphill movement of the sludge (Sengiland Ozakar, 2006). At higher the current density e. g., $0.42 \mathrm{~mA} / \mathrm{cm}^{2}$ amount of co-precipitation forming of $\mathrm{Zn}(\mathrm{OH})_{2}$ was so high. It is observed that with increasing the current density, the turbidity of wastewater was also increased. Thus, $0.36 \mathrm{~mA} / \mathrm{cm}^{2}$ considered the favourable current density for the electrocoagulation technique.

\subsection{Optimal Time}

Time is important parameters in the electrocoagulation process as it has a profound effect on energy consumption as well as pollutant removal efficiency (Gholami et al., 2019). In Fig. 4 we have represented the relationship between chromium removal efficiency and the processing time. The relationship shows that at the initial stage of the processing time chromium removal efficiency was gradually increased. For 6, 12 and $18 \mathrm{~h}$ removal efficiency of chromium was observed $27.8,63.4$ and $98.0 \%$, respectively and after that, the removal efficiency was decreased as the increased in time. This phenomenon was observed due to rapid oxidation of $\mathrm{Cr}^{3+}$ and formation of $\mathrm{Cr}(\mathrm{OH})_{3}$. At the beginning of electrocoagulation process, tiny particles tend to form floc but with the increase of process time, particle size turns into muscular form due to this tendency latter part of the electrocoagulation process chromium removal efficiency start to decrease (Moradi et al., 2020). A possible explanation is that after $18 \mathrm{~h}$ the 
precipitated chromium returns to the aqueous phase. For this reason, the removal efficiency of chromium by the electrocoagulation process decline and increased the TDS simultaneously. Therefore, $18 \mathrm{~h}$ was decided as the optimum time for chromium removal for the electrocoagulation process.

\subsection{Removal Efficiency at Optimal Conditions}

Table 1 represents the optimum data for the electrocoagulation process before and after treatment. To assess the quality of the treatment, several physicochemical parameters like $\mathrm{pH}$, TDS, BOD, chromium, turbidity, and EC were determined after all stages of treatments. It was found that after treatment the $\mathrm{pH}$, TDS, BOD, chromium, turbidity, and EC were $7.0,2756 \mathrm{mg} / \mathrm{L}, 780 \mathrm{mg} / \mathrm{L}, 6.9 \mathrm{mg} / \mathrm{L}, 57 \mathrm{NTU}$, and $8.7 \mathrm{mS}$, respectively. The value of $\mathrm{pH}$, TDS, and conductivity was higher in the treated sample compared to the raw sample. The possible explanation behind this is the rapid production of hydroxyl ion during the treatment process (Lakshmi and Sivashanmugam, 2013). The obtained removal efficiency for BOD, chromium, and turbidity was $64.6,98.0$ and $75.5 \%$, respectively. Mella et al., (2015) have observed maximum removal efficiency of chromium was $97.8 \%$ which is lower than this study. Table 1 shows that although there was a significant reduction of chromium in the wastewater but still higher according to ECR standard. The treatment process achieved a higher efficiency ofchromium removal, along with BOD and turbidity reduction.

Table 1: Data comparison between raw sample and treated sample

\begin{tabular}{lccc}
\hline \multicolumn{1}{c}{ Parameters } & Raw sample & Treated sample & ECR (1997) \\
\hline $\mathrm{pH}$ & $4.8 \pm 1.7$ & $7.0 \pm 1.9$ & $6-9$ \\
$\mathrm{TDS}(\mathrm{mg} / \mathrm{L})$ & $2248 \pm 39$ & $2756 \pm 47$ & 2100 \\
$\mathrm{BOD}(\mathrm{mg} / \mathrm{L})$ & $2200 \pm 27$ & $780 \pm 14$ & 250 \\
$\mathrm{Cr}(\mathrm{mg} / \mathrm{L})$ & $340.1 \pm 9$ & $6.9 \pm 1.8$ & 2.0 \\
Turbidity $(\mathrm{NTU})$ & $233 \pm 7$ & $57 \pm 3$ & - \\
Conductivity $(\mathrm{mS})$ & $7.5 \pm 1.3$ & $8.7 \pm 2.4$ & - \\
\hline
\end{tabular}

\section{CONCLUSIONS}

The batch-wise electrocoagulation process is a feasible solution for removing chromium from tannery wastewater. The process shows superior removal efficiency of pollutants in comparison with other techniques. Chromium from wastewater was co-precipitated with zinc oxides and removed from the water body and at optimized conditions removal efficiency was of $98.0 \%$. The biological oxygen demand and turbidity were removed $64.5 \%$ and $75.5 \%$, respectively. Total dissolved solids were slightly increased due to the generation of $\mathrm{ZnO}(\mathrm{OH})$ in the sludge sample as a zinc plate was used as the anode. This process could reduce pollution load at a significant level and chromium could be recovered at a large scale from the co-precipitation of zinc oxide for reuse.

\section{REFERENCES}

Aitbara A., Cherifi M., Hazourli S., and Leclerc J.P., 2014. Continuous treatment of industrial dairy effluent by electrocoagulation using aluminum electrodes. Desalin. Water Treat. 57(8), 3395-3404.

Aoudj S., Khelifa A., Drouiche N., and Hecini M., 2012. HF wastewater remediation by electrocoagulation process. Desalin Water Treat. 51, 1596-1602.

APHA, American Public Health Association, 2012. Standard Methods for the Examination of Water and Wastewater

Belay A. A., 2010. Impacts of chromium from Tannery effluent and evaluation of alternative treatment options. J. Environ. Prot. 1, 53-58

Bhatti M. S., Reddy A. S., Kalia R. K., and Thukral A. K., 2011. Modeling and optimization of voltage and treatment time for electrocoagulation removal of hexavalent chromium. Desalination 269(1-3), 157-162.

Chowdhury M., Mostafa M. G., Biswas T. K., Mandal A., and Saha A. K., 2015. Characterization of the Effluents from Leather Processing Industries.Environ. Process 2(1), 173-187.

El-Taweel Y. A., Nassef E. M., Elkheriany I., and Sayed D., 2015. Removal of Cr(VI) ions from wastewater by electrocoagulation using iron electrode. Egypt. J. Pet. 24(2), 183-192

Environmental Conservation Rules, ECR 1997. Ministry of Environment \& Forest (MoEF) Government of the People's Republic of Bangladesh

Ghernaout D., Naceur M. W., and Ghernaout B., 2011. A review of electrocoagulation as a promising coagulation process for improved organic and inorganic matters removal by electrophoresis and electroflotation. Desalin Water Treat. 28(1-3), 287-320.

Gholami P., Dinpazhoh L., Khataee A., and Orooji Y., 2019. Sonocatalytic activity of biochar-supported ZnO nanorods in degradation of gemifloxacin: Synergy study, effect of parameters and phytotoxicity evaluation. Ultrason. Sonochem. 55, 44-56. 
Kamaraj M., Srinivasan N. R., Assefa G., Adugna A. T., and Kebede M., 2020. Facile development of sunlit ZnO nanoparticles-activated carbon hybrid from pernicious weed as an operative nano-adsorbent for removal of methylene blue and chromium from aqueous solution: Extended application in tannery industrial wastewater. Environ. Technol. Innov.17, 100540. doi:10.1016/j.eti.2019.100540

Khaldi S., Lounici H., Drouiche M., and Drouiche N., 2017. Treatment of ointment pharmaceutical wastewater by electrocoagulation process. Desalin Water Treat.71, 152-158.

Kothai P., Meena A., Meenaloshini E., Revathy A., and Kumar N.V., 2019. Treatment of tannery effluent using groundnut shells.Int. Res. J. Eng. Tech. 6(3), 2395-0072.

Koushkbaghi S., Zakialamdari A., Pishnamazi M., Ramandi H. F., Aliabadi M., and Irani M., 2018. Aminated$\mathrm{Fe}_{3} \mathrm{O}_{4}$ nanoparticles filled chitosan/PVA/PES dual layers nanofibrous membrane for the removal of $\mathrm{Cr}(\mathrm{VI})$ and $\mathrm{Pb}(\mathrm{II})$ ions from aqueous solutions in adsorption and membrane processes. Chem. Eng. J. 337, 169-182.

Kumar D., Singh J., and Baleanu, D., 2017. A new numerical algorithm for fractional Fitzhugh-Nagumo equation arising in transmission of nerve impulses. Nonlinear Dyn.91(1), 307-317.

Kusku O., Rivas B. L., Urbano B. F., Arda M., Kabay N., and Bryjak M., 2014. A comparative study of removal of $\mathrm{Cr}(\mathrm{VI})$ by ion exchange resins bearing quaternary ammonium groups. J. Chem. Technol. Biotechnol. 89(6), 851-857.

Lefebvre O., and MolettaR., 2006. Treatment of organic pollution in industrial saline wastewater: A literature review. Water Res. 40(20), 3671-3682.

Lakshmi M., and Sivashanmugam P., 2013. Treatment of oil tanning effluent by electrocoagulation: Influence of ultrasound and hybrid electrode on COD removal.Sep. Purif. Technol., 116, 378-384.

Makwana, A. R., and Ahammed M. M., 2016. Continuous electrocoagulation process for the post-treatment of anaerobically treated municipal wastewater. Sep. Purif. Technol. 102, 724-733.

Mavrov V., Stamenov S., Todorova E., Chmiel H., and Erwe T., 2006. New hybrid electrocoagulation membrane process for removing selenium from industrial wastewater. Desalination 201(1-3), 290-296.

Mella B., Glanert A. C., and Gutterres M., 2015. Removal of chromium from tanning wastewater and its reuse. Process Saf. Environ. 95, 195-201.

Mohan D., 2006. Trivalent chromium removal from wastewater using low cost activated carbon derived from agricultural waste material and activated carbon fabric cloth.J. Hazard. Mater. 135, 280-295

Moradi M., Vasseghian Y., Arabzade H., and Khaneghah, A.M., 2020. Various wastewaters treatment by sonoelectrocoagulation process: A comprehensive review of operational parameters and future outlook. Chemosphere 263, 128314.

Obayomi K. S., Auta M., and Kovo A. S., 2020. Isotherm, kinetic and thermodynamics studies for adsorption of lead(II) onto modified Aloji clay. Desalin Water Treat. 181, 376-384.

Overah L. C., 2011. Biosorption of Cr (III) from aqueous solution by the leaf biomass of Calotropisprocera'Bombom'. J. Appl. Sci. Environ. 15(1), 87-95

Pal M., Malhotra M., Mandal M. K., Paine T. K., and Pal P., 2020. Recycling of wastewater from tannery industry through membrane-integrated hybrid treatment using a novel graphene oxide nanocomposite. J. Water Process. Eng. 36, 101324, doi:10.1016/j.jwpe.2020.101324

Saravanabhavan, S., Thanikaivelan P., Rao J. R., Nair B. U., and Ramasami T., 2004. Natural Leathers from Natural Materials: Progressing toward a New Arena in Leather Processing.Environ. Sci. Technol. 38(3), 871-879.

Sarker, B. C. Basak, B., and Islam, M. S., 2013. Chromium effects of tannery wastewater and appraisal of toxicity strength reduction and alternative treatment. Int. J. Agric. Res. 3(11), 23-35

Sengil, I.A., and Ozacar, M., 2006.Treatment of dairy wastewaters by electrocoagulation using mild steel electrodes.J. Hazard. Mater. 137:1197-1205.

Sivaram N. M., and Barik D., 2019. Toxic Waste from Leather Industries, Energy from Toxic Organic Waste for Heat and Power Generation, 55-67.

Society of Leather Technologist and Chemists, SLTC, 1996. Official Methods of Analysis, Northampton, UK.

Thakur C., Srivastava V. C., and Mall I. D., 2009. Electrochemical treatment of a distillery wastewater: Parametric and residue disposal study, Chem. Eng. J., 148(2-3), 496-505.

Yahya M. D., Abubakar H., Obayomi K. S., Iyaka Y. A., and Suleiman B., 2020. Simultaneous and continuous biosorption of $\mathrm{Cr}$ and $\mathrm{Cu}$ (II) ions from industrial tannery effluent using almond shell in a fixed bed column, Results in Engineering 6, 100113, doi:10.1016/j.rineng.2020.100113.

(C) 2021 the Authors. Journal of Engineering Science published by Faculty of Civil Engineering, Khulna University of Engineering \& Technology. This is an open access article under the terms of the Creative Commons AttributionNonCommercial-NoDerivatives License, which permits use and distribution in any medium, provided the original work is properly cited, the use is non-commercial and no Modifications or adaptations are made. 